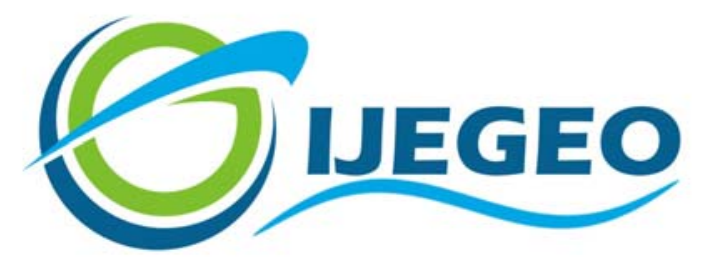

International Journal of Environment and Geoinformatics (IJEGEO) is an international, multidisciplinary, peer reviewed, open access journal.

\title{
Statistical Analyses of Wave Height and Wind Velocity Distributions for the Sea of Marmara
}

\author{
Tarkan Erdik and Serdar Beji \\ Editors \\ Prof. Dr. Cem Gazioğlu, Prof. Dr. Dursun Zafer Şeker, Prof. Dr. Ayşegül Tanık, \\ Prof. Dr. Şinasi Kaya, Assist. Prof. Dr. Volkan Demir
}

\section{Scientific Committee (2018)}

Assist. Prof. Dr. Abdullah Aksu, Prof. Dr. Bedri Alpar, Prof. Dr. Gülșen Altuğ, Prof. Dr. Lale Balas, Prof. Dr. Can Balas, Prof. Dr. Levent Bat, Prof. Dr. Bülent Bayram, Prof. Dr. Nuray Çağlar, Prof. Dr. Jadunandan Dash, Prof. Dr. A. Evren Erginal, Assoc. Prof. Dr. Ali Ertürk, Dr. Dieter Fritsch, Dr. Amin Gharehbaghi, Assoc. Prof. Dr. Tolga Görüm, Prof. Dr. Melike Gürel, Dr. Hakan Kaya, Prof. Dr. Fatmagül Kılıç, Assoc. Prof. Dr. Maged Marghany, Prof. Dr. Nebiye Musaoğlu, Prof. Dr. Masafumi Nakagawa, Prof. Dr. Haluk Özener, Prof. Dr. Erol Sarı, Prof. Dr. Elif Sertel, Prof. Dr. Nüket Sivri, Assoc. Prof. Dr. Füsun Balık Şanlı, Prof. Dr. Uğur Şanlı, Assoc. Prof. Dr. Hasan Özdemir, Prof. Dr. Taşkın Kavzoğlu Assoc. Prof. Dr. Oral Yağcı, Prof. Dr. Seyfettin Taş, Assoc. Prof. Dr. Ömer Suat Taşkın, Assoc. Prof. Dr. İ. Noyan Yılmaz, Assist. Prof. Dr. Baki Yokeş, Assit. Prof. Dr. Sibel Zeki 


\title{
Statistical Analyses of Wave Height and Wind Velocity Distributions for the Sea of Marmara
}

\author{
Tarkan Erdik $^{1^{*}}$, Serdar Beji ${ }^{2}$ \\ ${ }^{1}$ Faculty of Civil Engineering, Istanbul Technical University, Istanbul, Turkey \\ ${ }^{2}$ Faculty of Naval Architecture and Ocean Engineering, Istanbul Technical University, Istanbul, Turkey \\ Corresponding author* \\ E-mail : erdik@itu.edu.tr \\ Received 27 Nov 2017 \\ Accepted 28 Feb 2018
}

\begin{abstract}
The Sea of Marmara, a relatively small basin located between the Black Sea and the Aegean Sea with narrow seaways of the Bosphorus and the Dardanelles, has vital importance in coastal and ocean engineering activities due to substantial industrial development surrounding it and related sea traffic. Despite this importance, measurements concerning coastal engineering applications, in particular the wave climate, are quite scarce. Lack of essential data impairs the reliability of engineering works such as breakwaters and coastal protection structure designs. For a period of approximately one year between February 2013 and January 2014 Turkish Petroleum International Company (TPIC) carried out wave and wind measurements in the Sea of Marmara. The data were collected in 30-minute intervals throughout the one year span at the location of 41o04' $\mathrm{N}$ and 28o19' E with $50 \mathrm{~m}$ water depth. The present work analyses this rather unique data statistically for wind, wave height and energy conditions in the Sea of Marmara.
\end{abstract}

Keywords: Sea of Marmara, Wind stress, Wave height distribution, Wave Power Potential.

\section{Introduction}

The Sea of Marmara, a small virtually enclosed water mass located approximately between $40^{\circ} 20^{\prime} \mathrm{N}$ and $41^{\circ} 00^{\prime} \mathrm{N}$ latitudes and $27^{\circ} 00^{\prime} \mathrm{E}$ and $29^{\circ} 20^{\prime} \mathrm{E}$ longitudes, serves a connecting basin between Black Sea and Aegean Sea through the Straits of Istanbul and Çanakkale. Sea of Marmara is an inland sea, separating the peninsulas Thrace and Anatolia and connects the Black SeaMediterranean marine realms through the Turkish Strait System. The surface area is 11 $111 \mathrm{~km}^{2}$ (approximately rectangular $280 \mathrm{~km}$ $\mathrm{x} 80 \mathrm{~km}$ ) with the deepest point reaching approximately $1300 \mathrm{~m}$ from the surface (Figure 1) (Gazioğlu et al., 2002, Alpar et al., 2003).

Thorough knowledge about potential sea states in a certain area is indispensable for all activities related to the maritime sector. Sea state analyses are available from in-situ measurement data, numerical modelling, and various forecast models derived on empirical or mathematical models giving relations between wind and waves (Katalinic, et al., 2015). The sea states (generated by the wind) are mainly strong-minded by the wind speed and, in specific, the incline of the wind velocity which induces a force. Thus, understanding the temporal and spatial variations of the wind force regulated through different angles of incidence upon the sea surface is a fundamental issue. Another issue is the characteristic spectrum over which the wind force is converted into wave motion (Blackledge et al., 2013). Absence of systematic wave measurements for the Sea of Marmara causes a rather low reliability in coastal related studies. However, recently Turkish Petroleum International Company (TPIC) has carried out wave and wind measurements for a period of nearly one year between February 2013 and January 2014. The measurements were recorded by a single buoy deployed at location of $41^{\circ} 04^{\prime} \mathrm{N}$ and $28^{\circ} 19^{\prime}$ E with $50 \mathrm{~m}$ water depth. The location of the buoy, as shown in Fig. 1, is at the northern boundary of the Sea of Marmara nearly $3.3 \mathrm{~km}$ south of the shoreline. The wave conditions in this 
particular location are obviously determined by southerly winds which blow across meaningful fetch lengths. The northerly winds do not generate any appreciable waves since the fetch is virtually zero: the wind blows from the land near the location of the buoy out into the sea. Therefore, the data is sifted carefully and only the waves recorded for southerly winds are considered in the analyses.

\section{Study area and wave data}

TPIC carried out wave measurements in the Sea of Marmara at location 41o04' $\mathrm{N}$ and $28019^{\prime} \mathrm{E}$, where the water depth is $50 \mathrm{~m}$. This particular location is quite close to the northern shores as can be seen from Fig. 1. The data was collected for nearly one year period between February 2013 and January 2014 with 30 minute-time intervals. Records yield the spectrally based significant wave height Hm0, maximum wave height Hmax, mean wave direction, peak period $T p$, mean wave period based on the first moment T01, wave period based on the second moment T02, wind speed, wind direction. In this study, $\mathrm{HmO}$, mean wave direction, wind speed, wind direction, and T02 is employed.

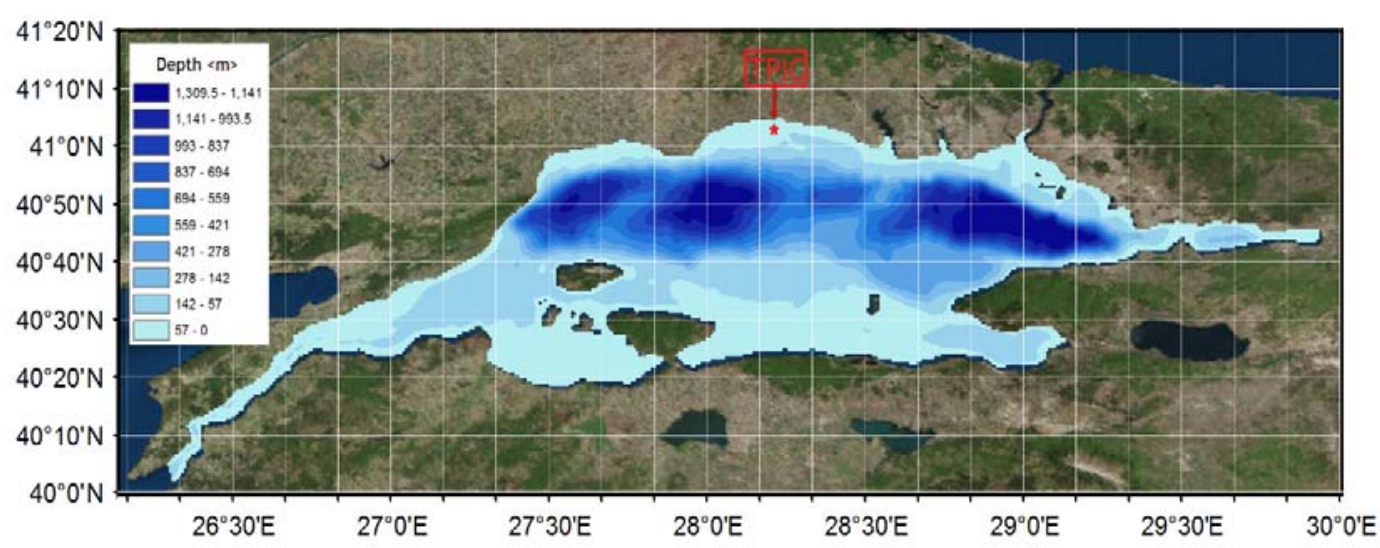

Fig. 1: Sea of Marmara and location of TPIC Buoy.

The definitions of the above quantities are given in terms of the moments $m_{i}$ of the energy density spectrum $S(f)$ :

$m_{i}=\int_{f \min }^{f \max } f^{i} S(f) d f \quad($ Eq. 1$)$

Longuet-Higgins (1952) first showed that narrow-band ocean waves possess a Rayleigh distribution, from which it can be derived that $H_{m 0}=4 \sqrt{m_{0}}$, where $m_{0}=\int S(f) d f$ corresponds to the zeroth moment in equation (1). The spectral wave periods are given by

$T_{i j}=\left(\frac{m_{i}}{m_{j}}\right)^{\frac{1}{j-i}}, i<j$

According to equation (2) the mean wave period based on the first moment is given by

$$
T_{01}=m_{0} / m_{1}
$$

likewise, the mean wave period based on the second moment is

$$
T_{02}=\sqrt{m_{0} / m_{2}} \text {. }
$$

The wave energy flux per crest-width per wavelength in deep water is calculated as $P=\frac{\rho_{w} g^{2}}{64 \pi} T_{m-1} H_{m o}^{2}$, where $\mathrm{P}$ is energy flux per crest-width or power per crest-width in Watt $/ \mathrm{m}, T_{m-1}(\mathrm{~m}-1 / \mathrm{m} 0)$ energy mean wave period, $\rho$ is the density of sea water, $g$ is the acceleration of gravity. Due to the lack of $T_{m-1}$ measurement in the dataset this period is taken as $T_{02}$.

\section{Wind, Wave Climate and Wave Energy Potential of Marmara Sea}

The wind roses for the frequency of wind direction and for average and maximum wind speeds as obtained from the data of TPIC for the entire measurement period of nearly one year are depicted with 300 
intervals in Fig. $2 \mathrm{a}$ and $2 \mathrm{~b}$. From the wind rose for wind direction frequency it is seen that the winds predominantly blow from the $\mathrm{N}-\mathrm{E}$ band with a probability of $56 \%$. On the other hand, the maximum wind speeds show quite a diverse distribution, reaching $15 \mathrm{~m} / \mathrm{s}$ in directions $\mathrm{N}, \mathrm{S}, \mathrm{NNE}, \mathrm{WNW}$. In particular the north and south directions both have nearly the same observed maximum wind speeds.
Considering the location of the measurement buoy and the associated fetch lengths shown in Fig. 3 it is obvious that the meaningful wave heights must be measured only for winds blowing from the sector covering approximately the range between $\mathrm{SE}$ and SW directions
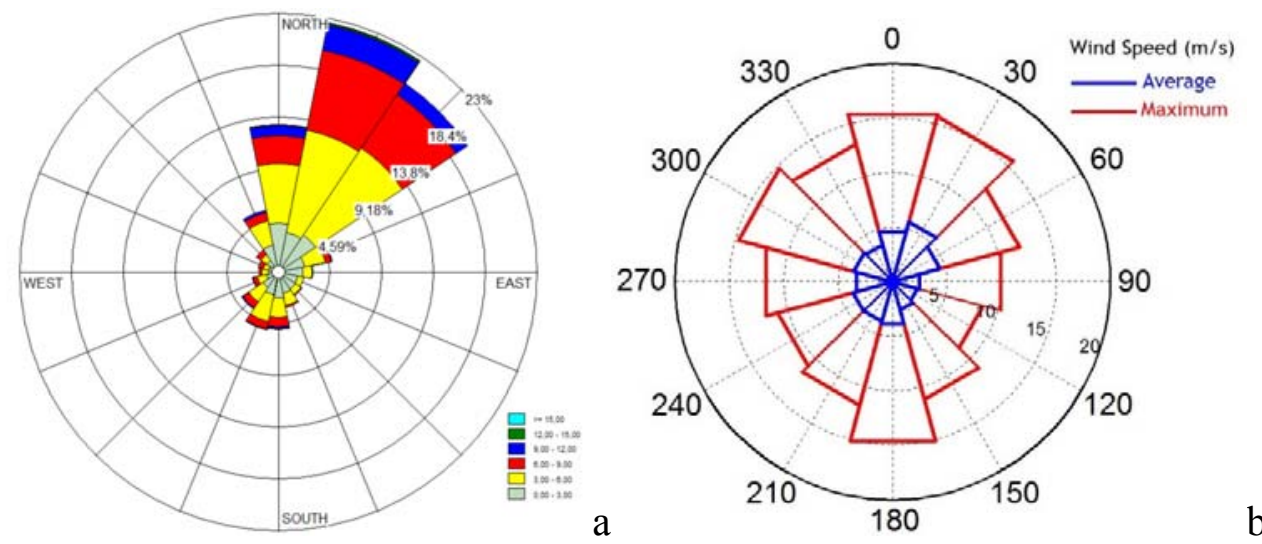

Fig. 2 Wind rose (a) for the frequency of wind direction occurrence (b) for the mean (blue) and maximum (red) wind speed per direction.

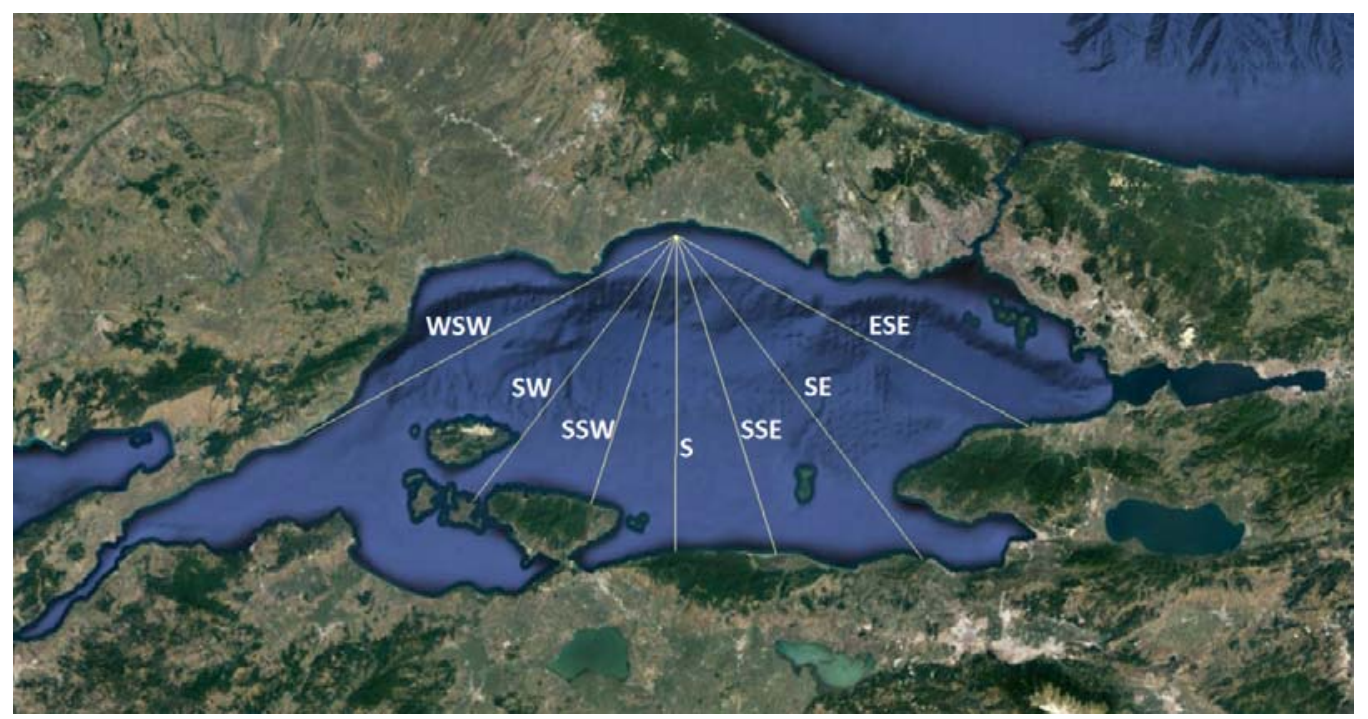

Fig. 3 Fetch lengths across the Sea of Marmara for the location of the measurement buoy. 
To support this argument the wave roses for the frequency of occurrence direction and mean and maximum wave heights per direction are given in Fig. 4a and 4b. Clearly, the highest measured waves come from the SSE-S-SSW band, where the strong winds blow from (Fig.2b) over relatively long fetches (Fig. 3). From all available data 90\% of the measured wave heights are equal or

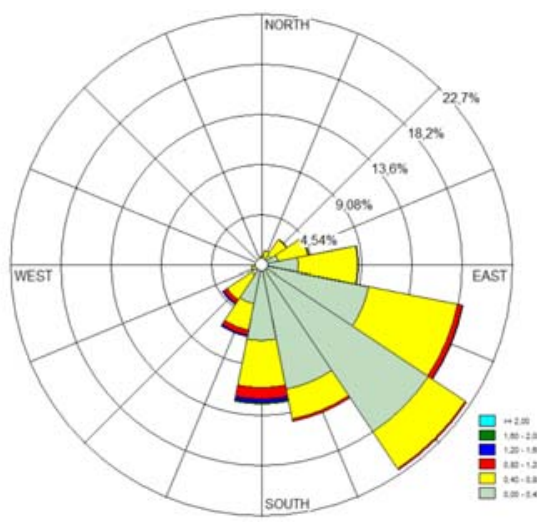

less than $0.55 \mathrm{~m}$ while only $1 \%$ of the wave data is higher than $1 \mathrm{~m}$. $68 \%$ of the times waves approach from the SE band; but the highest waves come from the S-SSW directions. The observation that measured maximum wave heights are associated with the S-SSW directions is in accord with the earlier presupposition due to the location of the buoy.

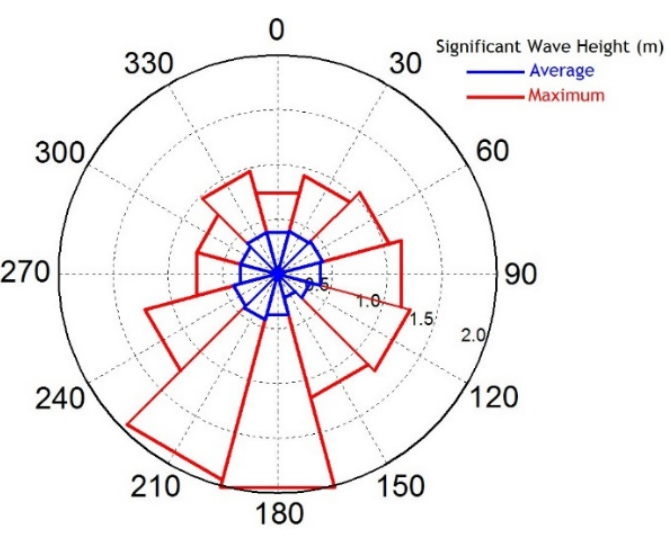

b

Fig. 4 Wave rose (a) for the frequency of wave direction occurrence (b) for the mean (blue) and maximum (red) wave height per direction.

Graphs representing the wave power potential are given in Fig. 5a and 5 b. Obviously, these graphs are mimicking the corresponding graphs in Fig. $4 \mathrm{a}$ and $4 \mathrm{~b}$. Therefore, as expected, the most energetic waves come from the S and SSW directions. The average wave power per crest-width is calculated to be approximately $0.28 \mathrm{~kW} / \mathrm{m}$

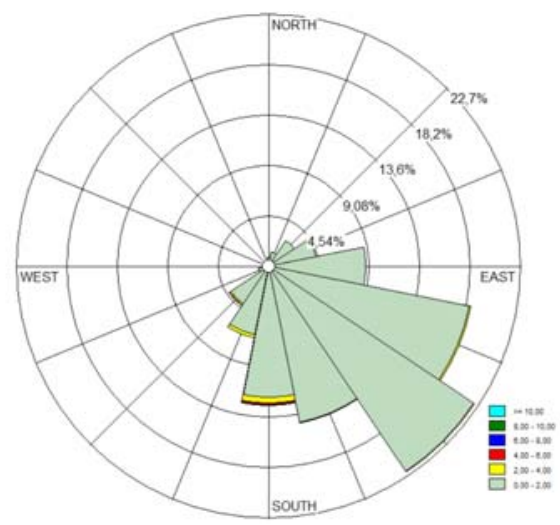

a for the one year long data. An earlier work (Abdollahzadehmoradi, 2017) performed using MIKE 21 for the period 1994-2014 about the wave power potential of the Sea of Marmara estimated the overall annual mean wave power as $0.27 \mathrm{~kW} / \mathrm{m}$, which is quite in line with the present value based on measurements.

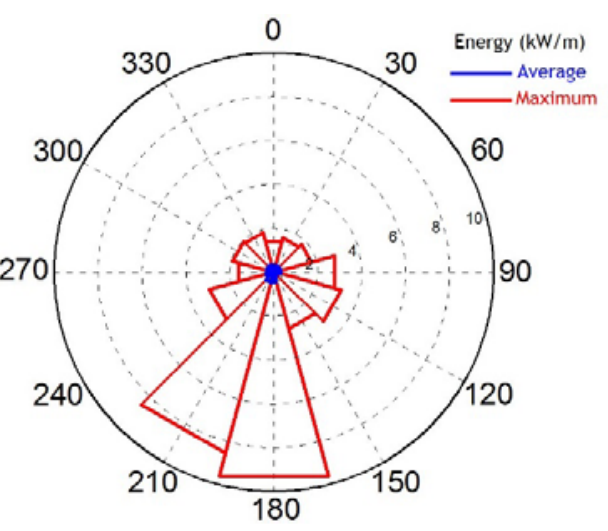

b

Fig. 5 Energy rose (a) for the frequency of wave direction occurrence (b) for the mean (blue) and maximum (red) wave energy per direction. 
This relatively low value agrees with the relatively calm wave climate of the Sea of Marmara, which being an enclosed basin has quite low wave energy potential in comparison to open oceans. Further, it is calculated that only $1 \%$ of the time, or approximately 3.6 days in a year, the average levels of energy flux exceeds $2.40 \mathrm{~kW} / \mathrm{m}$.

The complete time series of the significant wave height $H_{m 0}$ and mean wave period $T_{02}$ are further analyzed to estimate their joint probability density function. In Fig 6 , the joint distribution of $p\left(H_{m 0}, T_{02}\right)$ is shown as computed for the sectors SSW-S which are deemed to contain the meaningful measurements. That is to say, the wave heights and periods measured for southerly

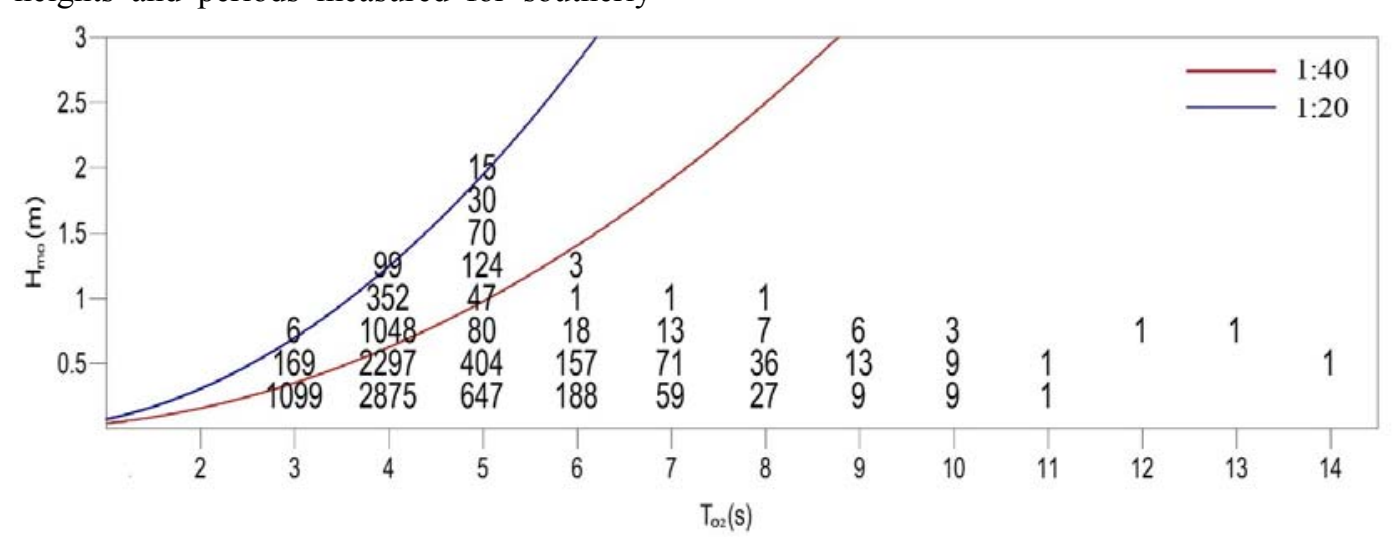

Fig. 6 Bilateral distribution of $H_{m o}$ versus $\mathrm{T}_{02}$.

\section{Long Term Distributions}

Long-term distributions of wave heights, wind speed and wave energy are of vital importance to properly analysis long-term evolution of coastal processes and to design stability of structures. Long-term analysis has two main purposes: to arrange and to extrapolate the data set to extreme values of occurring at low probabilities of exceedance (Kamphuis, 2010). In this study, Log-normal, Weibull (with both 2 and 3 parameters) and Gamma probability distribution functions (pdf) are employed and compared with each other. Among others, Weibull pdf with 3 parameters is found to be the best-fitted pdf as a linear correlation. Therefore, only the Weibull pdfs are presented here. The winds as the measurement buoy is located very near the north coastal boundary.

In the figure the frequency of occurrence is scaled by $1: 10000$. The solid lines represent constant wave steepness, $H_{m 0} / L_{m 0}=$ $2 \pi H_{m 0} / g T_{02}^{2}$ (wavelength computed for deep water) for $1 / 20$ (blue) and 1/40 (red). Battjes (1972) indicated that limiting wave steepness range from $1 / 16$ to $1 / 20$ in random waves. In this study, it is observed that virtually all the waves fall below wave steepness of $1 / 20$. The most frequent wave has $H_{m 0}=0.25 \mathrm{~m}$ and $T_{02}=4 \mathrm{~s}$. The highest waves occur for $H_{m 0}=2 \mathrm{~m}$ and $T_{02}=5 \mathrm{~s}$ and for a total duration of 13 hours per year. correlations of the Weibull pdfs for different $\alpha$ values for wind speed, $\mathrm{H}_{\mathrm{m} 0}$, and wave energy flux are given in Figs. 7, 8 and 9, respectively. In the graphs, $W=\left(\ln \frac{1}{Q}\right)^{1 / \alpha}$ where $Q$ is the probability of exceedance and $\alpha$ is the calibration parameter which provides the possible best linear relationship and is determine by trial-and-error. For Weibull pdf $\mathrm{H}_{\mathrm{TR}}=\gamma+\beta\left(\ln \frac{1}{\mathrm{Q}}\right)^{1 / \alpha}$ in which $\mathrm{Q}=1 / \lambda \mathrm{T}_{\mathrm{R}}$. Herein, $\lambda$ is the number of events per year, $T_{R}$ the return period, and $\mathrm{H}_{\mathrm{TR}}$ the wave height for a return period of $T_{R}$. Since the collected data is for one year long the pdfs should be viewed with caution. 
Weibull distribution for the wind speed

with $\alpha=2.6$

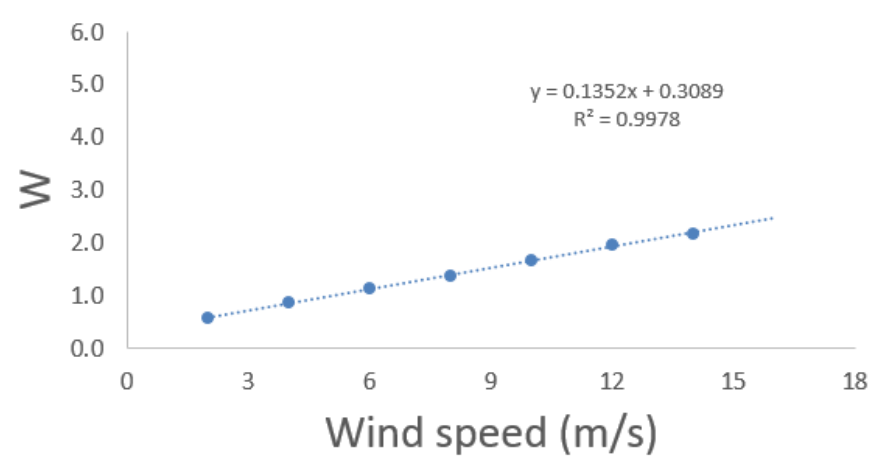

Fig. 7 Weibull distribution for wind speed

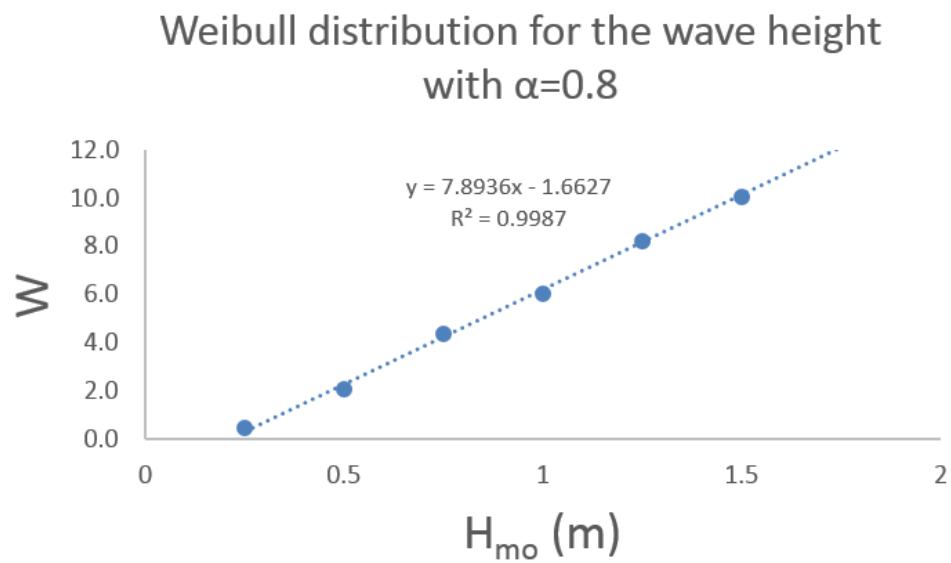

Fig. 8 Weibull distribution for wave height

Weibull distribution for the wave energy with $\alpha=1.15$

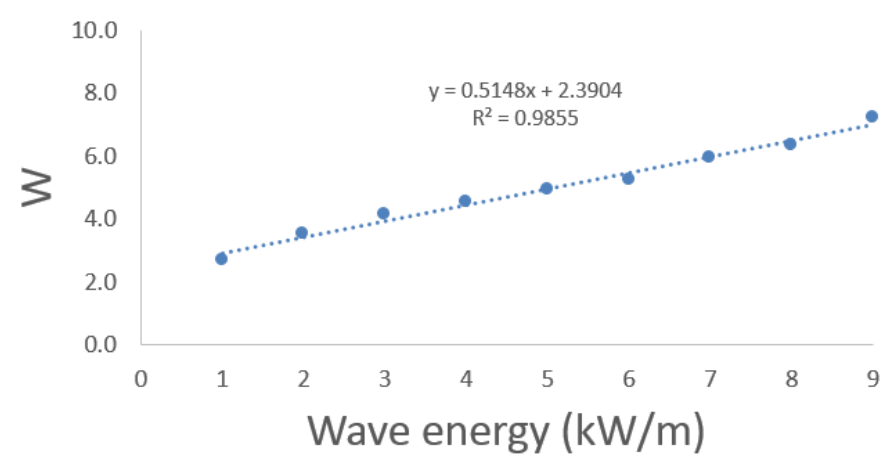

Fig. 9 Weibull distribution for wave energy 
Normally, the linear correlations given in Figures 7-9 should be in the form $y=a x$ so that $y=0$ when $x=0$. However; this necessary condition is sacrificed to obtain better fits for more meaningful parts of the graphs; namely, the higher wave energy regions with higher $\mathrm{W}$ values.

\section{Conclusions}

The data measured by TPIC in the Sea of Marmara for nearly one year duration has been analyzed. First, it is observed that dominant winds come from predominantly N-E band with a probability of $56 \%$. However, due to the location of the measurement buoy the southerly winds generate the waves meaningful for the analyses.

After sifting the data for southerly winds it is calculated that $90 \%$ of the measured wave heights are equal to or less than $0.55 \mathrm{~m}$ while only $1 \%$ is higher than $1 \mathrm{~m}$. For $68 \%$ of the time waves approach from the SE band and the maximum wind speed and wave height are observed to come from the southern direction.

The average energy flux per crest-width is approximately $0.28 \mathrm{~kW} / \mathrm{m}$ for the one year long data and in close agreement with a previous estimate $0.27 \mathrm{~kW} / \mathrm{m}$.

The joint probability distributions $p\left(H_{m 0}, T_{02}\right)$ are drawn for the sectors SSW-S which are deemed to contain the meaningful measurements. The most frequent wave is found to be $H_{m 0}=0.25 \mathrm{~m}$ and $T_{02}=4 \mathrm{~s}$. The highest waves occur for $H_{m 0}=2 \mathrm{~m}$ and $T_{02}=5 \mathrm{~s}$ and for a total duration of 13 hours per year.

Finally, wind speed, wave height and wave energy flux parameters are all seen to correlate well with Weibull pdf.

\section{Acknowledgements}

The authors acknowledge the measured data provided by the Turkish Petroleum International Company (TPIC). We also thank graduate student Yasin Abdollahzadehmoradi for making the figures.

\section{References}

Abdollahzadehmoradi, Y., Özger, M., and Altunkaynak, A. (2017) Long-term Macro-scale Assessment of Wave Power of Black Sea by an Optimized Numerical Model, Iranian Journal of Science and Technology, Transactions of Civil Engineering, accepted to be published.

Alpar, B., Altınok, Y., Gazioğlu, C. and Yücel, ZY. (2003) Tsunami hazard assessment in Istanbul, Journal of Black Sea/Mediterranean Environment, Vol.9(1):3-29.

Battjes, J. A. (1972). Long-term wave height distributions at seven stations around the British Isles. Deutsche Hydrografische Zeitschrift, 25(4), 179-189.

Bidlot, J-R, (2016), Ocean wave model output parameters https://software.ecmwf.int/wiki/download /attachments/19661682/wave_parameters. pdf?version $=1 \&$ modificationDate $=14938$ 04133220\&api $=$ v2

Blackledge, J., Coyle, E., Kearney, D., McGuirk, R. and Norton, B. (2013) Estimation of Wave Energy from Wind Velocity. IAENG Engineering Letters, Issue 4: 158-170.

Frostick, L. E., McLelland, S. J. and Mercer, T. G. (Eds.). (2011). Users guide to physical modelling and experimentation: Experience of the HYDRALAB network. CRC Press.

Gazioğlu, C., Gökaşan, E., Algan, O., Yücel, ZY., Tok, B. and Doğan, E. (2002). Morphologic features of the Marmara Sea from multi-beam data, Marine Geology Vol.190(1-2):397-420.

Hofland, B., Chen, X., Altomare, C. and Oosterlo, P. (2017). Prediction formula for the spectral wave period $\mathrm{T} \mathrm{m}-1,0$ on mildly sloping shallow foreshores. Coastal Engineering, 123, 21-28.

Kamphuis, J. W. (2010). Introduction to coastal engineering and management (Vol. 30). World Scientific Publishing Co Inc.

Katalinic, M., Corak, M. and Parunov, J. (2015). Analysis of wave heights and 
wind speeds in the Adriatic Sea, Maritime Technology and Engineering (Guedes Soares and Santos (Eds), 1389-1394.

Longuett-Higgins, M. S. (1952). On the statistical distribution of the heights of sea waves. J. Mar. Research, 11(3), 245266.

Van de Walle, B. (2003). Wave run-up on rubble mound breakwaters (Doctoral dissertation, Ghent University). Van de Walle, B. (2003). Wave run-up on rubble mound breakwaters (Doctoral dissertation, Ghent University). 